\title{
Molecular Epidemiology of Ralstonia solanacearum Species Complex Strains Causing Bacterial Wilt of Potato in Uganda
}

\author{
Abdulwahab Abdurahman, ${ }^{1,2,3}$ Monica L. Parker, 1,2 Jan Kreuze, 1,4 John G. Elphinstone, 5 Paul C. Struik, ${ }^{3}$ \\ Andrew Kigundu, ${ }^{6}$ Esther Arengo, ${ }^{6}$ and Kalpana Sharma ${ }^{1,2, \dagger}$ \\ ${ }^{1}$ Consultative Group for International Agricultural Research, Research Program on Roots, Tubers and Bananas, Lima, Peru \\ ${ }^{2}$ Sub-Saharan Africa Regional Office, International Potato Center, Nairobi, Kenya \\ ${ }^{3}$ Centre for Crop Systems Analysis, Plant Sciences, Wageningen University and Research, Wageningen, The Netherlands \\ ${ }^{4}$ Crop and Systems Sciences Division, International Potato Center, Lima, Peru \\ 5 National Agri-Food Innovation Campus, Fera Science Ltd, Sand Hutton, York, United Kingdom \\ ${ }^{6}$ National Agricultural Research Laboratories, Kawanda, Uganda \\ Accepted for publication 28 June 2019.
}

\begin{abstract}
Bacterial wilt (BW) caused by the Ralstonia solanacearum species complex (RSSC) is a serious threat to potato production in Uganda. However, little is known about the extent of the disease and the type of the pathogen strains involved. A nationwide survey was conducted to study BW prevalence and incidence in potato, and potato tuber and stem samples of potential alternative hosts were collected for pathogen isolation. DNA was extracted from pure cultures for genetic diversity studies. The pathogen was phylotyped by multiplex PCR; then, a subset of isolates was typed at sequevar level. Isolates of the same sequevar were then haplotyped using multilocus tandem repeat sequence typing (TRST) schemes. BW prevalence and incidence in potato farms were 81.4 and
\end{abstract}

ABSTRACT

Members of the Ralstonia solanacearum species complex (RSSC) cause bacterial wilt (BW) disease on a wide range of crops of economic importance (Hayward 1994), jeopardizing sustainable crop production. Strains within the RSSC are highly destructive owing to their virulence, persistence, wide host range, and broad geographical distribution (Elphinstone 2005; Mansfield et al. 2012). They account for $\$ 1$ billion in annual losses worldwide on potato alone (Elphinstone 2005). Latently infected propagation materials, such as potato seed tubers, are known to be a source of long-distance spread of the pathogen, and they pose a threat to crop production and contribute to pathogen dispersal (Buddenhagen 1986; Janse 1996; Janse et al. 2004) (latent infection being plant tissue infected by plant pathogenic bacteria that shows no disease symptom on host plants [Hayward 1974; Swanson et al. 2007]). Studies have shown that strains within RSSC can persist in soil, water, and alternative hosts for many years (Alvarez et al. 2008; van Overbeek et al. 2004). The lack of effective chemical treatments for BW in association with the long-term persistence of the bacterium in infected fields is a challenge in the development of effective management strategies for this destructive disease.

${ }^{\dagger}$ Corresponding author: K. Sharma; kalpana.sharma@cgiar.org

Funding: Funding support for this work was provided by German Federal Ministry for Economic Cooperation and Development (BMZ) project number 16.7860.6001.00 and contract number 81206684 .

*The $\boldsymbol{e}$-Xtra logo stands for "electronic extra" and indicates that three supplementary tables are published online.

The author(s) declare no conflict of interest. distributed under the CC BY-NC-ND 4.0 International license.
$1.7 \%$, respectively. Three RSSC phylotypes were identified, with the majority of the strains belonging to Phylotype II $(80 \%)$ followed by Phylotype I (18.5\%) and III (1.5\%). Phylotype I strains belonged to Sequevar 31, and Phylotype II strains belonged to Sequevar 1. Potatoassociated Phylotype II Sequevar 1 strains were more diverse (27 TRST haplotypes) than nonpotato Phylotype I (5 TRST haplotypes). Mapping of TRST haplotypes revealed that three TRST haplotypes of Phylotype II Sequevar 1 strains play an important epidemiological role in BW of potato in Uganda being disseminated via latently infected seed.

Keywords: bacteriology, etiology, population biology
Potato is a staple food and source of income for many rural smallholder farmers and urban families in Uganda (Kaguongo et al. 2008). Production and acreage have increased, making potato one of the fastest growing industries in the country (Uganda Bureau of Statistics and Macro International Inc. 2015). Nevertheless, the potato sector in Uganda is still underdeveloped, and it is faced with low productivity of $4.2 \mathrm{tha}^{-1}$ on average or less compared with other African countries, such as Ethiopia, Kenya, Rwanda, and Tanzania (9 to $13.1 \mathrm{t} \mathrm{ha}^{-1}$ ), and the world (20.1 t/ha) (FAOSTAT 2017). This is largely because of yield losses attributed to use of pathogeninfected seed (Gildemacher et al. 2009).

Losses caused by RSSC on potato are estimated to be 30 to $100 \%$ in Uganda (Alacho and Akimanzi 1993; Kakuhenzire et al. 2013; Low 1997). BW in Uganda was first reported on groundnut in 1930 (McClean 1930) and potato in 1958 (Simbwa-Bunnya 1972). Since then, BW has been reported in major potato-producing areas (Alacho and Akimanzi 1993; Kakuhenzire et al. 2013; Low 1997; Tusiime et al. 1996) as well as in other nonpotato crop-producing areas on tomato, tobacco, eggplant, sweet pepper, hot pepper, groundnut, nakati (Solanum aethiopicum), nightshade, and other crops, such as eucalyptus (Elphinstone 2005; Fouché-Weich et al. 2006; Katafiire et al. 2005; Opio 1988). Although BW is endemic in Uganda, no systematic information is available on the extent and nature of the disease in the Ugandan potato production system.

Historically, $R$. solanacearum strains were classified into five races based on differences in host range (Buddenhagen et al. 1962) and six biovars based on differences in biochemical properties (Hayward 1964). The race/biovar classification was replaced by the phylotype-sequevar system of Fegan and Prior (2005). Here, a multiplex PCR was designed and used to rapidly classify strains into one of four major lineages termed phylotypes. Within each phylotype, individual sequevars can be identified according to sequence similarity within the endoglucanase (egl) gene. The 
phylotypes are believed to correlate to strains' geographic origins: Phylotype I (Asia), Phylotype II (America), Phylotype III (Africa), and Phylotype IV (Indonesia). $R$. solanacearum underwent a taxonomic revision (Safni et al. 2014). In this latest classification, both phenotypic and genotypic data led to the description of three species within the RSSC: $R$. solanacearum, which includes all Phylotype II strains; Ralstonia pseudosolanacearum, which houses Phylotypes I and III; and Ralstonia syzygi correlating to Phylotype IV strains (Safni et al. 2014).

Molecular tools used to monitor RSSC epidemics include multilocus sequence typing (Wicker et al. 2012) and multiplelocus variable number tandem repeat analysis (MLVA) (Guinard et al. 2017; N'Guessan et al. 2013; Parkinson et al. 2013). MLVA allows for the discrimination among closely related strains of RSSC within the same sequevar. Abdurahman et al. (2017) used the MLVA (tandem repeat sequence typing [TRST]) scheme of Parkinson et al. (2013) combined with two loci of N'guessan et al. (2013) for geographically mapping the distribution of Phylotype IIB Sequevar 1 strain involved in the potato BW epidemic in Ethiopia and traced the epidemiological strain causing a BW outbreak. Ravelomanantsoa et al. (2018) demonstrated the importance of MLVA typing schemes for mapping BW pathogen distribution and epidemiological inferences in Madagascar.

Hayward (1990) and Simbwa-Bunnya (1972) reported RSSC Biovar 1 from tobacco, Biovar 2 from potato, and Biovars 3 and 4 from groundnut in Uganda. Race 3 Biovar 2 (the potato brown rot strains, which by inference, were Phylotype II Sequevar 1 strains) isolated from potato (Lemaga et al. 2001, 2005) and Race 3 Biovar 3 from groundnut (Opio 1988; Poussier et al. 2000) and Biovar 3 hrprestriction fragment length polymorphism (RFLP) group II (which by inference, is Phylotype I) strains from eucalyptus (FouchéWeich et al. 2006) have also been reported from Uganda. However, it is also not known if Biovars 1, 3, and 4 are important on potatoes in Uganda. Apart from these reports, which had a very limited scope for sample numbers and locations, little is known about the genetic diversity of RSSC strains and their geographical distribution in Uganda.

The potato seed system in Uganda is largely informal and unrestricted in regional and cross-border movement of seed potato. The unregulated seed movement in the regions within Uganda and cross-border poses a great threat in disseminating RSSC strains to uninfected areas and may introduce new strains from abroad as well. It is, therefore, important to have a comprehensive understanding of the strain types being disseminated with the seed movement, patterns of dispersal, and disease spread. Insight in these aspects is a prerequisite to design effective management strategies that control and limit the spread of BW.

Here, we isolated RSSC typical colonies, extracted DNA from the isolates, and sequentially performed RSSC universal amplicon detection, phylotyping, sequevar typing, and TRST analysis of the isolates, with the particular aims to (i) assess the prevalence and incidence of $\mathrm{BW}$ on potato, (ii) characterize the genetic diversity of RSSC strains isolated from potato and other alternative hosts, and (iii) generate an RSSC distribution map that may provide epidemiological inferences to develop future BW management interventions.

\section{MATERIALS AND METHODS}

Selection of survey districts and villages. The survey districts and villages were selected by the team of the National Agricultural Research Laboratories (NARL), Kawanda, Uganda, in consultation with knowledgeable district agricultural officers before the field survey. The number of samples per district was based on the importance (area coverage) of either potato or alternative crop hosts of RSSC. A total of 19 districts were selected for the survey: 12 districts for potato (Table 1) and 7 districts for alternative hosts (Table 2). Among the 12 potato districts, 5 districts fall in the western region (146 farms), 4 fall in the eastern region (90 farms), 2 fall in the central region (12 farms), and 1 falls in the northern ( 25 farms) region, and they account for at least $72 \%$ of the total potato production of the country (Uganda Bureau of Statistics and Macro International Inc. 2015); however, the majority of the alternative hosts fall in the central region, except for Ngora district in the eastern region.

Assessment of BW prevalence and incidence in potato crops and tuber sampling. While crossing preselected villages, potato fields were randomly selected along rural roads for evaluation. To prevent the spread of the pathogen between surveyed potato fields, boots were sprayed with $5 \%$ sodium hypochlorite solution, hands were disinfected with $70 \%$ ethanol, and gloves were changed between handling samples. BW incidence per field was calculated by dividing the number of wilted potato hills by the total number of potato hills (a potato hill being all potato plants emerging from a single mother tuber) (Struik and Wiersema 1999) sampled per potato field of a unit area. Prevalence of BW per district was calculated by dividing the number of wilted fields by the total number of surveyed fields. A total of 273 potato fields were surveyed in 12 districts (Mubende, Mityana, Kween, Kapchorwa, Bulambuli, Mbale, Zombo, Kabale, Kisoro, Kasese, Kabarole, and Kyenjejo) (Table 1). Fields were closely inspected for typical BW symptoms, and wilt incidence was recorded; tuber samples were collected for the pathogen isolation. Up to five wilting potato hills were randomly selected per field, and two tubers were sampled per hill, making up a composite of up to 10 tubers per potato field. Then, tubers were wrapped in paper towel, put in a labeled paper bag, and kept at room temperature until processing for bacterial isolation. A note was taken if the farmer was producing potatoes intended for sale as seed.

Sampling of alternative hosts. A total of 106 samples from eight alternative crop hosts (chili, eggplant, garden egg, ginger, green pepper, hot pepper, nakati, and tomato) and two weed hosts (African nightshade and Sodom apple) were collected (Table 2). The sampling procedure was as stated above for potato crops, except that a composite sample of up to five plants per visited field was selected randomly and the stem (one stem per plant) base was cut, wrapped in paper towels, put in a labeled paper bag, and kept at room temperature until processing for bacterial isolation. Wilt disease incidence and severity data were not collected, because the sampling was done regardless of whether the plant showed wilting or not.

TABLE 1. Potato survey by region and district with altitude range covered, number of samples collected and processed, and number of Ralstonia solanacearum species complex (RSSC) isolates per district from the 2017 survey in Uganda

\begin{tabular}{lcccc}
\hline $\begin{array}{l}\text { Region and } \\
\text { district }\end{array}$ & $\begin{array}{c}\text { Altitude range } \\
\text { (masl) }\end{array}$ & $\begin{array}{c}\text { Number of } \\
\text { samples }\end{array}$ & $\begin{array}{c}\text { Number of } \\
\text { samples } \\
\text { processed for } \\
\text { RSSC isolation }\end{array}$ & $\begin{array}{c}\text { Number } \\
\text { of RSSC } \\
\text { isolates }\end{array}$ \\
\hline $\begin{array}{l}\text { Central } \\
\text { Mubende }\end{array}$ & $1,324-1,394$ & 4 & 4 & 0 \\
$\quad \begin{array}{c}\text { Mityana } \\
\text { Eastern }\end{array}$ & $1,132-1,685$ & 8 & 6 & 3 \\
$\quad$ Kween & $2,135-2,559$ & 27 & 24 & 19 \\
Kapchorwa & $1,971-2,541$ & 11 & 11 & 10 \\
Bulambuli & $1,914-2,233$ & 20 & 20 & 16 \\
$\quad$ Mbale & $1,902-1,971$ & 32 & 24 & 17 \\
Northern & & & & \\
$\quad$ Zombo & $1,524-1,699$ & 25 & 18 & 10 \\
Western & & & & \\
$\quad$ Kabale & $1,805-2,490$ & 68 & 57 & 55 \\
Kisoro & $1,804-2,357$ & 42 & 36 & 28 \\
Kasese & $1,600-1,778$ & 14 & 10 & 5 \\
Kabarole & $1,312-1,600$ & 12 & 8 & 1 \\
$\quad$ Kyenjejo & $1,260-1,334$ & 10 & 10 & 2 \\
Total & & 273 & $228^{\mathrm{a}}$ & $166^{\mathrm{b}}$ \\
\hline
\end{tabular}

a Of 273 samples collected, only 228 were processed.

b Of 228 processed samples, only 166 were pure culture RSSC isolates. 
Isolation of RSSC strains and DNA extraction. Sample washing, processing of plant tissue matrix for bacterial concentration, and isolation on semiselective medium from South Africa (SMSA) and casamino acid-peptone-glucose (CPG) agar media were as described by Abdurahman et al. (2017). DNA was extracted from 205 presumptive $R$. solanacearum colonies grown (166 and 39 isolated from potato and alternative hosts, respectively) on CPG agar media for $48 \mathrm{~h}$ using the DNeasy Blood and Tissue kit (Qiagen) following the manufacturer's recommendations.

Identification and classification of $R$. solanacearum phylotype of presumptive $R$. solanacearum isolates. All presumptive Ralstonia isolates were screened using the RSSCspecific primer pairs 759/760 designed by Opina et al. (1997), and they were phylotyped using the RSSC multiplex PCR described by Fegan and Prior (2005). The PCR was run with the following cycling conditions: initial denaturation of $15 \mathrm{~min}$ at $95^{\circ} \mathrm{C} ; 30$ cycles of $30 \mathrm{~s}$ at $94^{\circ} \mathrm{C}, 1 \mathrm{~min}$ at $59^{\circ} \mathrm{C}$, and $1 \mathrm{~min}$ at $72^{\circ} \mathrm{C}$; and final extension of $10 \mathrm{~min}$ at $72^{\circ} \mathrm{C}$ on a $\mathrm{C} 1000$ Touch thermal cycler (Biorad).

Sequevar typing. For sequevar typing of the isolates, a 750-bp virulence-associated $e g l$ gene fragment was amplified from genomic DNA using Endo-F and Endo-R primers (Fegan and Prior 2005). The PCR was run using Fermentas PCR Mix (2×), $0.5 \mu \mathrm{M}$ Endo-F and Endo-R, and $2 \mu \mathrm{l}$ of genomic DNA in a $50-\mu \mathrm{l}$ reaction. The PCR was run on a C1000 Touch thermal cycler (Biorad) with the following cycling conditions: initial denaturation of 9 min at $96^{\circ} \mathrm{C} ; 30$ cycles of 1 min at $95^{\circ} \mathrm{C}, 1 \mathrm{~min}$ at $70^{\circ} \mathrm{C}$, and $2 \mathrm{~min}$ at $72^{\circ} \mathrm{C}$; and final extension of $10 \mathrm{~min}$ at $72^{\circ} \mathrm{C}$. The PCR product ( $750 \mathrm{bp}$ ) was then cleaned using the Wizard SV Gel and PCR Cleanup system (Promega) following the kit protocol before being sent for sequencing to a provider (Eurofins Genomics). The same Endo-F and Endo-R primers were used for sequencing.

The consensus sequences generated from sense and antisense partial egl sequences were combined into a multifasta file along with a range of $e g l$ reference sequences from the NCBI database, covering 53 known sequevars within the RSSC, and aligned with the ClustalW multiple alignment tool in BioEdit Sequence Alignment Software; then, the aligned sequences were used to generate a phylogenetic tree in MEGA6 software (Tamura et al. 2013). Construction of the phylogenetic tree and sequevar assignment were done as described by Abdurahman et al. (2017). In addition, all strains that clustered with Sequevar 1 reference strains IPO1609 and JT516 were individually tested with a computer program (S1 $R$. solanacearum typing program) for typing $R$. solanacearum Sequevar 1 and Sequevar 2 strains (Stulberg and Huang 2016).

TRST. Seven variable number tandem repeat (VNTR) loci from the RS2-MLVA9 scheme described by Ravelomanantsoa et al. (2018); L504, L539, L540, and L563 from Parkinson et al. (2013); IPO100, IP3143, and M1936 from N'guessan et al. (2013), and seven MLVA schemes of Guinard et al. (2017) were selected to resolve $R$. solanacearum Phylotype II $(n=44)$, and $R$. pseudosolanacearum Phylotype I strains $(n=26)$. Simplex PCR reaction and cycling conditions were as described in Abdurahman et al. (2017) for $R$. solanacearum VNTRs, whereas simplex PCR and cycling conditions for VNTR locus M1936 and the seven R. pseudosolanacearum VNTRs was as described for locus IPO100 in Guinard et al. (2017). The $2 \times$ PCR mix (Thermofisher Scientific) was used in all cases. The amplified PCR products were run on $1.5 \%$ agarose gel stained with GelRed, and the target amplicon was cut under ultraviolet light, immediately cleaned with Wizard SD gel and PCR clean-up system, and sequenced using sequencing primers indicated in Supplementary Table S1 by a sequencing service (Macrogen). Tandem repeat sequences were counted manually after aligning the sequences with the start and finish sequence definitions by Parkinson et al. (2013) and using the ClustalW alignment tool in BioEdit software (Supplementary Table S2). A

TABLE 2. Alternative hosts survey by region and districts, altitude range covered, number of samples collected and processed, and number of Ralstonia solanacearum species complex (RSSC) isolates per district from 2017 survey in Uganda

\begin{tabular}{|c|c|c|c|c|c|}
\hline $\begin{array}{l}\text { Region and } \\
\text { district }\end{array}$ & Altitude range (masl) & Alternative host crop & $\begin{array}{l}\text { Number of } \\
\text { samples }\end{array}$ & $\begin{array}{l}\text { Number of samples } \\
\text { processed for } \\
\text { RSSC isolation }\end{array}$ & $\begin{array}{c}\text { Number of RSSC } \\
\text { isolates }\end{array}$ \\
\hline \multicolumn{6}{|l|}{ Central } \\
\hline \multirow{2}{*}{ Mityana } & & Eggplant & 5 & & 1 \\
\hline & & Chili & 2 & & 2 \\
\hline Butambala & $1,100-1,200$ & Ginger & 19 & 19 & 0 \\
\hline \multirow[t]{3}{*}{ Kayunga } & $1,036-1,074$ & Tomato & 5 & 15 & 2 \\
\hline & & Green pepper & 1 & & 1 \\
\hline & & Sodom apple & 2 & & 1 \\
\hline \multirow[t]{3}{*}{ Mukono } & $1,125-1,232$ & Tomato & 8 & 18 & 2 \\
\hline & & Eggplant & 7 & & 4 \\
\hline & & Green pepper & 3 & & 3 \\
\hline \multirow[t]{2}{*}{ Wakiso } & $1,111-1,221$ & Tomato & 7 & 20 & 4 \\
\hline & & Eggplant & 12 & & 3 \\
\hline \multirow{3}{*}{ Nakaseke } & & Green pepper & 2 & & 0 \\
\hline & & African nightshade & 2 & & 2 \\
\hline & & Sodom apple & 1 & & 1 \\
\hline \multirow[t]{2}{*}{ Luwero } & $1,170-1,173$ & Eggplant & 1 & 2 & 0 \\
\hline & & $\begin{array}{l}\text { Nakati (Solanum } \\
\text { aethiopicum) }\end{array}$ & 1 & & 0 \\
\hline \multicolumn{6}{|l|}{ Eastern } \\
\hline \multirow[t]{3}{*}{ Ngora } & $1,037-1,082$ & Ginger & 2 & 4 & 0 \\
\hline & & Tomato & 1 & & 0 \\
\hline & & $\begin{array}{c}\text { Nakati (Solanum } \\
\text { aethiopicum) }\end{array}$ & 1 & & 0 \\
\hline Total & & & 106 & 106 & $39^{\mathrm{a}}$ \\
\hline
\end{tabular}

a Of 106 processed samples, only 39 were pure culture RSSC isolates. 
string of tandem repeat numbers in the order of L504-L539-L540IPO100-IP3143-M1936 for $R$. solanacearum and L131-L233L133-L574-L3461-L266-L985 for $R$. pseudosolanacearum represents TRST profiles (alleles).

Data analysis. Allelic diversity at each locus was calculated using the unbiased estimator of Nei (1978): $h=1-\sum x_{i}^{2}[n /(n-1)]$, where $x_{i}$ is the frequency of the $i$ th allele at the locus, $n$ is the number of isolates, and $n /(n-1)$ is a correction for bias in small samples (Nei 1978; Selander et al. 1986); the analysis was performed using the built-in algorithm in LIAN Linkage Analysis (http://guanine.evolbio.mpg.de). The overall discriminatory power of the TRST scheme was tested with the Hunter-Gatson index of diversity (HGDI) (Hunter and Gatson 1988) and the Adjusted Hunter-Gatson index (Mokrousov 2017) in Microsoft Excel. The relationship between the isolates was analyzed using eBURST v3 to define profiles and clonal clusters using default settings. The standardized index of association $\left(I_{\mathrm{A}}^{\mathrm{S}}\right)$ between different alleles of the loci was calculated using LIAN Linkage Analysis (http://guanine.evolbio.mpg.de) (Haubold and Hudson 2000) with 100,000 Monte Carlo simulations settings to test the null hypothesis of linkage equilibrium $\left(I_{\mathrm{A}}^{\mathrm{S}}=0\right)$.

\section{RESULTS}

BW prevalence and incidence in potato farms. In ware potato farms, BW prevalence ranged from $85 \%$ in Zombo to $100 \%$ in Bulambuli, Kapchorwa, and Kween districts; in the Kyenjejo district, there were no wilting symptoms observed. The overall prevalence was $81.2 \%$ (Table 3). BW incidence ranged from $0.76 \%$ (334 wilted plants per 1 ha considering the planting density of 44,000 plants per $1 \mathrm{ha}$ ) in Kabarole to $4.05 \%$ (1,782 wilting plants/ ha) in the Mbale district, with overall average of $2.08 \%$.

In seed potato farms, BW prevalence ranged from $25 \%$ in the Mubende district to $100 \%$ in Bulambuli, Kween, Kabarole, and Kisoro districts, with an overall average of $81.5 \%$. BW incidence ranged from $0.001 \%$ in the Mubende district to $3.36 \%$ in the Bulambuli district, with an overall incidence of $1.32 \%$ (Table 3 ).

Detection and identification of bacterial isolates. Of 228 potato samples processed for bacterial isolation, 166 isolates were confirmed by multiplex PCR to belong to RSSC and identified as $R$. solanacearum Phylotype II, except for 3 isolates. The three isolates that were collected from the Zombo district in northwestern Uganda were identified as $R$. pseudosolanacearum Phylotype III (Table 3).

Of 106 alternative host samples processed for bacterial isolation, 39 of them were confirmed as RSSC isolate and identified as R. pseudosolanacearum Phylotype I strains by the phylotyping scheme, except for a single isolate from Capsicum annuum collected from a research field at NARL-Kawanda in the Wakiso district, which was identified as $R$. solanacearum Phylotype II (Table 3).

Sequevar typing. Phylogenetic analyses of the egl gene sequences of $80 R$. solanacearum Phylotype II strains were clustered with Sequevar 1 reference strains (Fig. 1). All of these strains were also individually confirmed to be $R$. solanacearum Phylotype II Sequevar 1 strains by the computer program of Stulberg and Huang (2016).

Thirty-six $R$. pseudosolanacearum Phylotype I strains that were isolated from alternative hosts clustered with reference Sequevar 31 strains JT51 and RUN801 (Rodrigues et al. 2012), although the bootstrap value for the topology was not significant, and three $R$. pseudosolanacearum Phylotype III strains from potato did not align with any published Sequevars 1 to 60 (Fig. 2).

Multilocus TRST. The analysis of the seven VNTR loci sequences resolved $44 R$. solanacearum Phylotype II Sequevar 1 strains into 27 TRST haplotypes (a haplotype here being isolates with identical TRST profiles; $R$. solanacearum-TRST1 to -27) (Table 4). TRST haplotypes $R$. solanacearum-TRST1 $(n=5$ : Kabale, Bulambuli, Kween, and Mbale districts) and $R$. solanacearum-TRST2 ( $n=5$ : Kisoro, Kabale, Bulambuli, Mbale, and Zombo districts) were the most frequent TRST haplotypes followed by $R$. solanacearum-TRST4 ( $n=4$ : Bulambuli, Kween, and Mbale districts) and $R$. solanacearum-TRST5 ( $n=4$ : Kabale, Kyenjejo, and Bulambuli districts).

The TRST analysis of the seven VNTR loci of $R$. pseudosolanacearum Phylotype I strains identified five TRST haplotypes (R. pseudosolanacearum-TRST), with $R$. pseudosolanacearumTRST1 ( $n=17$ : Mukono, Wakiso, and Nakaseke districts) being the most common followed by $R$. pseudosolanacearum-TRST2 ( $n=6$ : Nakaseke and Mityana districts) (Table 4). R. pseudosolanacearumTRST3, R. pseudosolanacearum-TRST4, and $R$. pseudosolanacearum-TRST5 were each represented by one isolate (Supplementary Table S3).

Allelic diversity, discriminatory power, and linkage disequilibrium. For $R$. solanacearum Phylotype II loci, Locus IPO100 had the highest allelic diversity $(h=0.83)$ followed by L563 ( $h=0.41$ ), classifying the loci as highly and moderately discriminatory, respectively, according to the classification of Sola et al. (2003). L504, L539, L540, and M1936 were poorly discriminatory, whereas IP3143 was not polymorphic at all (Table 5). Of the seven R. pseudosolanacearum Phylotype I VNTR loci used in this study, only L266 $(h=0.37)$ was moderately

TABLE 3. Summary of bacterial wilt prevalence and incidence in ware and seed potato farms from the 2017 survey in Uganda

\begin{tabular}{|c|c|c|c|c|c|c|c|c|}
\hline \multirow[b]{3}{*}{ Region and district } & \multicolumn{4}{|c|}{ Ware potato } & \multicolumn{4}{|c|}{ Seed potato } \\
\hline & \multirow[b]{2}{*}{ No. of farms } & \multirow[b]{2}{*}{ Prevalence $(\%)$} & \multicolumn{2}{|c|}{ Incidence $(\%)$} & \multirow[b]{2}{*}{ No. of farms } & \multirow[b]{2}{*}{ Prevalence $(\%)$} & \multicolumn{2}{|c|}{ Incidence $(\%)$} \\
\hline & & & Average & Range & & & Average & Range \\
\hline \multicolumn{9}{|l|}{ Central } \\
\hline Mityana & 8 & 87.5 & 0.92 & $0.00-2.70$ & 0 & - & - & - \\
\hline Mubende & 0 & $-{ }^{\mathrm{a}}$ & - & - & 4 & 25 & 0.001 & $0.00-0.004$ \\
\hline \multicolumn{9}{|l|}{ Eastern } \\
\hline Bulambuli & 17 & 100 & 2.53 & $0.04-20.02$ & 3 & 100 & 3.36 & $0.75-8.36$ \\
\hline Kapchorwa & 11 & 100 & 3.79 & $0.94-19.80$ & 0 & - & - & - \\
\hline Kween & 23 & 100 & 3.23 & $0.30-23.40$ & 4 & 100 & 2.70 & $0.90-6.75$ \\
\hline Mbale & 32 & 93.75 & 4.05 & $0.00-25.20$ & 0 & - & - & - \\
\hline \multicolumn{9}{|l|}{ Northern } \\
\hline Zombo & 20 & 85 & 1.02 & $0.00-5.40$ & 5 & 80 & 1.24 & $0.00-2.57$ \\
\hline \multicolumn{9}{|l|}{ Western } \\
\hline Kabale & 55 & 92.73 & 3.49 & $0.00-15.00$ & 13 & 84.62 & 1.21 & $0.00-4.85$ \\
\hline Kabarole & 11 & 54.55 & 0.76 & $0.00-5.62$ & 1 & 100 & 0.03 & $0.00-0.00$ \\
\hline Kasese & 14 & 85.72 & 1.40 & $0.00-4.50$ & 0 & - & - & - \\
\hline Kisoro & 35 & 94.29 & 1.75 & $0.00-12.59$ & 7 & 100 & 1.16 & $0.08-4.05$ \\
\hline Kyenjejo & 2 & 0.00 & 0.00 & $0.00-0.00$ & 8 & 62.50 & 0.85 & $0.00-2.25$ \\
\hline Total & 228 & 81.23 & 2.08 & & 45 & 81.51 & 1.32 & \\
\hline
\end{tabular}

a Absence of bacterial wilt prevalence and incidence because of no ware or seed potato farms in the respective districts. 
discriminatory, whereas the remaining ones were either very poorly discriminatory (L131, L574, and L985) or not polymorphic at all (L233, L133, and L3461). The analysis of HGDI of the combined multilocus TRST scheme showed high and moderate diversity within $R$. solanacearum Phylotype II $(\mathrm{HGDI}=0.96)$ and $R$. pseudosolanacearum Phylotype I (HGDI = 0.53), respectively.

Phylogeography of TRST haplotypes. Phylotype I $R$. pseudosolanacearum-TRST haplotypes were distributed in four districts of the central region: $R$. pseudosolanacearum-TRST1, $R$. pseudosolanacearum-TRST2, and R. pseudosolanacearumTRST3 in Nakaseke; $R$. pseudosolanacearum-TRST1, $R$. pseudosolanacearum-TRST4, and $R$. pseudosolanacearum-TRST5 in Wakiso; R. pseudosolanacearum-TRST1 in Mukono; and $R$. pseudosolanacearum-TRST2 in Mityana districts (Table 4).

Mapping of the $R$. solanacearum-TRST haplotypes to respective sampling sites revealed that the western, eastern, and northern

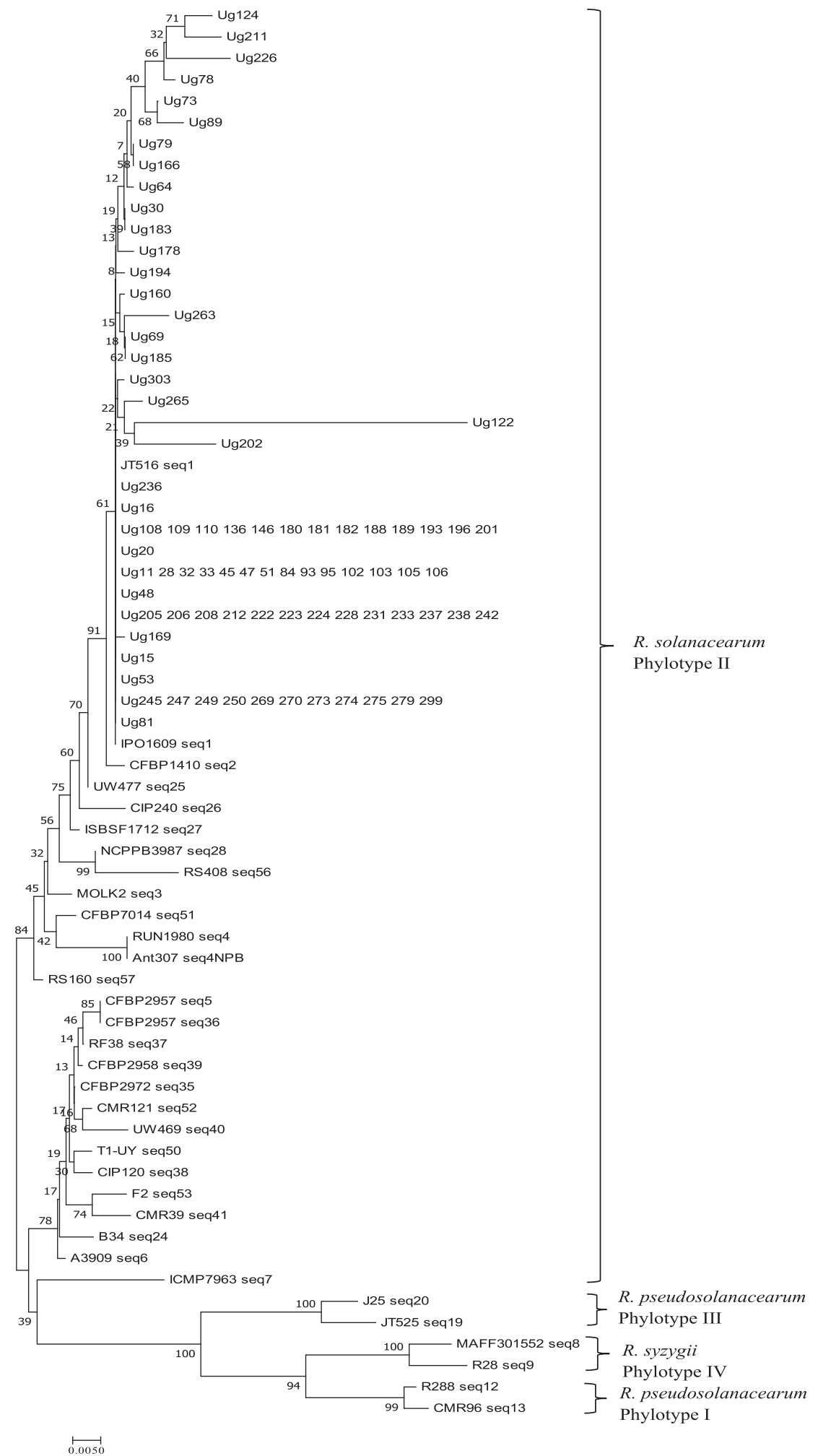

Fig. 1. Phylogenetic tree of partial endoglucanase (egl) gene sequences of 80 Ralstonia solanacearum Phylotype II isolates from potato and alternative hosts and 33 reference strains from the NCBI database. Isolates that were collected from Uganda in 2017 are prefixed "Ug," and Ug with different serial numbers indicates different isolates. Ug isolates with different serial numbers in a single line have the same egl sequence. 
regions contained 15, 12, and 3 haplotypes, respectively (Table 4). When combined with the dominant seed potato distribution patterns from western to eastern regions and from eastern to northern regions based on Figure 3, it became apparent that three $R$. solanacearum Phylotype II strains represented by $R$. solanacearum-TRST1, $R$. solanacearum-TRST2, and $R$. solanacearum-TRST5 were cross-regionally more important in Uganda (Fig. 3). $R$. solanacearum-TRST1 was identified from districts in western and eastern regions, whereas $R$. solanacearum-TRST2 was identified from the western, eastern, and northern regions. $R$. solanacearum-TRST5 was restricted to the western and eastern regions.

\section{DISCUSSION}

BW was first reported in 1958 in Uganda (Simbwa-Bunnya 1972); however, there were no country-wide BW monitoring

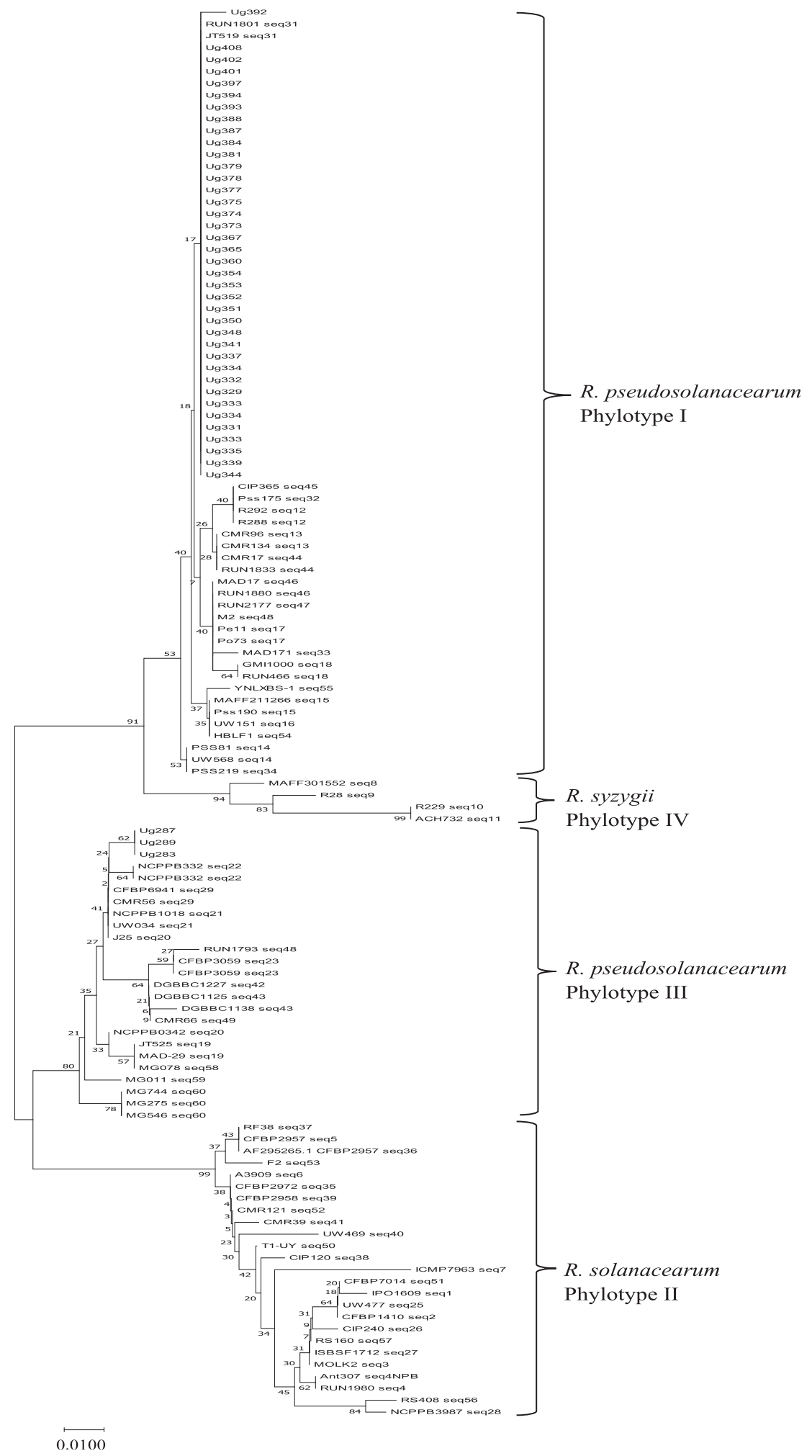

Fig. 2. Phylogenetic tree of partial endoglucanase gene sequences of 41 Ralstonia pseudosolanacearum Phylotype I and III isolates from alternative hosts and potato, respectively, and 74 reference strains from the NCBI database. Isolates that were collected from Uganda in 2017 are prefixed "Ug," and Ug with different serial numbers indicates different isolates. 
studies reported. Our study has confirmed its spread in all major potato-growing regions of the country, with a prevalence of $72.8 \%$ in ware potato farms and $50 \%$ in seed potato farms. The disease is encroaching into the northern region of the country, where potato has been introduced. Population structure of the RSSC in the country was composed of $R$. solanacearum (Phylotype II) and $R$. pseudosolanacearum (Phylotypes I and III), with $R$. solanacearum Sequevar 1 endemic to the country in potato and the most epidemic strain of potato BW. This is the first report providing a detailed overview of $\mathrm{BW}$ status, population structure and distribution of RSSC, and molecular epidemiology of RSSC strains causing BW of potato in Uganda.

BW control ranked as the highest-priority issue in potato production in Sub-Saharan Africa in 2007 (Fuglie 2007), whereas Kenyan and Ugandan farmers ranked BW as the highest priority disease in a 2004 to 2005 survey (Gildemacher et al. 2009).

TABLE 4. Summary of hosts of the Ralstonia solanacearum species complex (RSSC) with their respective phylotype, Sequevar, and tandem repeat sequence typing (TRST) haplotype from the 2017 survey in Uganda

\begin{tabular}{|c|c|c|c|c|}
\hline Region and district & Host of RSSC ${ }^{a}$ & RSSC strains & Sequevar & TRST haplotypes $^{\mathrm{b}}$ \\
\hline \multicolumn{5}{|l|}{ Central } \\
\hline \multicolumn{5}{|l|}{ Mubende $^{c}$} \\
\hline Mityana & Tomato, eggplant, chili & Phylotype I (Rps) ${ }^{\mathrm{d}}$ & 31 & \multirow[t]{2}{*}{ Rps-TRST2 } \\
\hline Kayunga & $\begin{array}{l}\text { Tomato, eggplant, garden egg, green pepper, } \\
\text { Sodom apple }\end{array}$ & Phylotype I (Rps) & 31 & \\
\hline Mukono & Tomato, eggplant, green pepper & Phylotype I (Rps) & 31 & Rps-TRST1 \\
\hline Wakiso & Tomato, eggplant & Phylotype I (Rps) & 31 & Rps-TRST1, -4 , and -5 \\
\hline \multicolumn{5}{|l|}{ Luweroc } \\
\hline \multicolumn{5}{|l|}{ Eastern } \\
\hline Kween & Potato & Phylotype II (Rs) & 1 & Rs-TRST1, $-4,-6,-16$, and -27 \\
\hline Kapchorwa & Potato & Phylotype II (Rs) & 1 & Rs-TRST14 \\
\hline Bulambuli & Potato & Phylotype II (Rs) & 1 & Rs-TRST1, $-2,-4,-5,-10,-15$, and -18 \\
\hline \multicolumn{5}{|l|}{ Western } \\
\hline Kabale & Potato & Phylotype II (Rs) & 1 & $\begin{array}{l}\text { Rs-TRST1, -2, }-3,-5,-7,-8,-12,-17,-19 \text {, } \\
-21,-22 \text {, and }-23\end{array}$ \\
\hline Kisoro & Potato & Phylotype II (Rs) & 1 & Rs-TRST2, -11 , and -24 \\
\hline Kasese & Potato & Phylotype II (Rs) & 1 & Rs-TRST25 \\
\hline Kabarole & Potato & Phylotype II (Rs) & 1 & \\
\hline Kyenjejo & Potato & Phylotype II (Rs) & 1 & \\
\hline
\end{tabular}

${ }^{a}$ Hosts in which the RSSC strain was confirmed of potential RSSC hosts sampled (Tables 1 and 2 have detailed information).

b Only RSSC strains of interest were included in multilocus variable number of tandem repeats sequence analysis.

c Districts where RSSC strain was not detected.

${ }^{\mathrm{d}}$ Rs, R. solanacearum; Rps, Ralstonia pseudosolanacearum.

e Sequevar is not determined, because the endoglucanase gene sequences did not cluster with a known sequevar.

TABLE 5. Range of tandem repeat counts, number of alleles, allelic diversity of variable number tandem repeat loci, and overall discriminatory power of tandem repeat sequence typing schemes for 45 Ralstonia solanacearum Phylotype II and 26 Ralstonia pseudosolanacearum Phylotype I isolates from the 2017 survey in Uganda

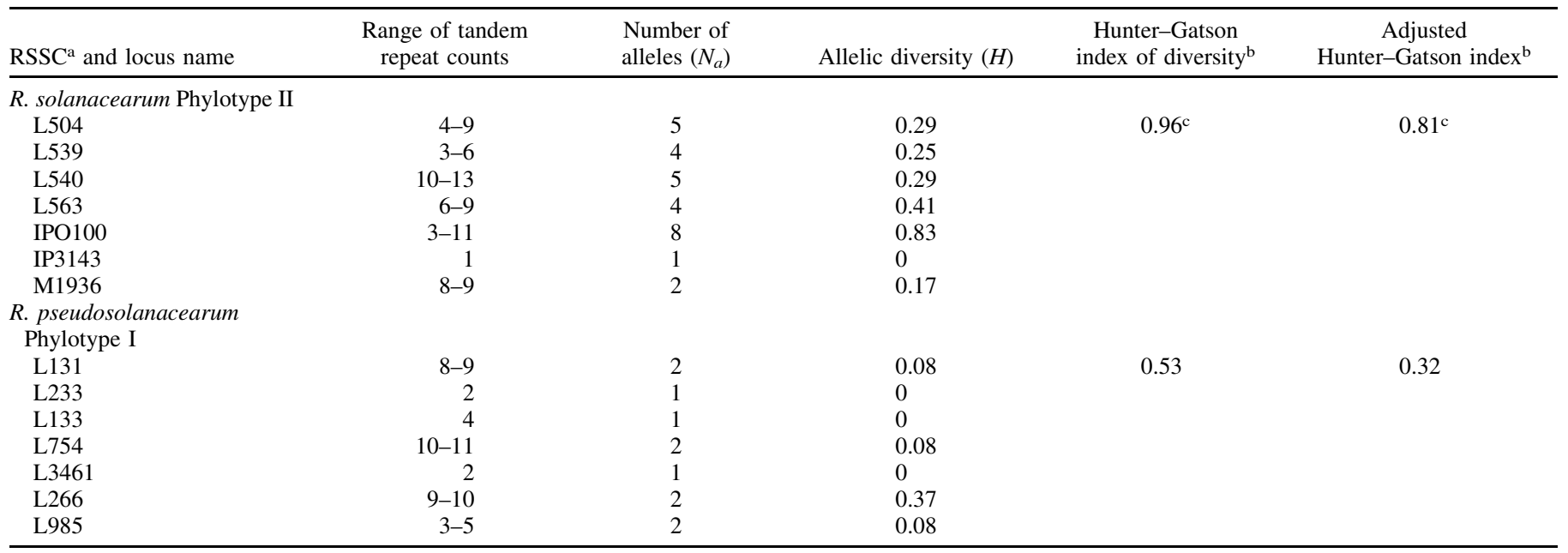

a RSSC, $R$. solanacearum species complex.

b Analysis is based on inclusion of loci per phylotype.

c Significant Hunter-Gatson index of diversity and Adjusted Hunter-Gatson index for R. solanacearum Phylotype II. 
According to Namugga et al. (2017), survey respondents in Kabale $(47.5 \%)$ and Kisoro $(36 \%)$ districts mentioned BW as a major potato production constraint in Uganda. This study confirmed the high BW prevalence and incidence in Kabale and Kisoro districts, which are primary hub of basic and early-generation seed for the whole country (Kansiime et al. 2016). Furthermore, this study also revealed high incidence and prevalence of BW in the secondary seed potato-producing districts (Kween, Kapchorwa, and Mbale) of the eastern highlands and the newly emerging potato-producing district (Zombo) in the northern region. This has an important implication for the epidemiology of the disease in the country, because the pathogen could continue to be spread through latently infected seed potatoes to the rest of the country given the lack of a seed-testing scheme.

Our finding of $R$. solanacearum Phylotype II Sequevar 1 is consistent with previous reports of Race 3 Biovar 2 strains by Kakuhenzire et al. (2013) and Lemaga et al. (2001, 2005) from potatoes in the highlands. The dominance of $R$. pseudosolanacearum Phylotype I strains on alternative hosts in the lower-altitude districts found in this research is also consistent with reports of Fouché-Weich et al. (2006) and Poussier et al. (2000), who reported Phylotype I Sequevar 31 strain NCPPB-1486 (Wicker et al. 2012) and Biovar 3 (which belongs to Phylotype I) strain, respectively, from Uganda. However, to our knowledge, this is the first time that $R$. pseudosolanacearum Phylotype III is reported in Uganda. It is also important to note that none of the isolates extracted from potatoes were identified as $R$. pseudosolanacearum Phylotype I, indicating that these strains are not the relevant epidemiological strains in the highlands. R. pseudosolanacearum Phylotype I strains are known to thrive better in tropical lowlands (Buddenhagen 1986; Elphinstone 2005), which was confirmed by this study, because all $R$. pseudosolanacearum Phylotype I strains were restricted to Solanaceous crops grown in the lowland districts $(1,036$ to 1,232 meter above sea level [masl]) (Table 1). R. pseudosolanacearum Phylotype I egl Sequevar 31, which dominates the isolates from alternative hosts in Uganda, was also reported by Chesneau et al. (2018), N'guessan et al. (2013), and Yahiaoui et al. (2017) to be the most prevalent and most virulent of Phylotype I egl Sequevar that they studied in Mayote Islands, French Guyana, and Indian Ocean Islands, respectively.

Phylotype III strains are believed to originate from Africa, and they are reported to be endemic in Cameroun (Mahbou Somo Toukam et al. 2009), Ivory Coast (N'Guessan et al. 2013), and the Democratic Republic of Congo (DRC) (Elphinstone 2005; Fegan and Prior 2005; Ravelomanantsoa et al. 2018; Wicker et al. 2012). However, despite the expectation that Phylotype III strains would dominate in Africa, they were few in Uganda, because only $1.5 \%$ of 205 isolates were identified as Phylotype III. Our finding is consistent with Phylotype III reports in Cameroun (Mahbou Somo Toukham et al. 2009) and Ivory Coast (N'Guessan et al. 2013), where only a minority of isolates (18 and $1.8 \%$, respectively) were Phylotype III.

In the DRC, potatoes are widely produced in the higher-altitude areas of North Kivu Province (Beni, Lubero, and Masisi territories) and often supplied to the northern region of Uganda. The exclusive identification of $R$. pseudosolanacearum Phylotype III strains in the Zombo district bordering the DRC indicates that the strains were either newly introduced from the DRC along the border with latently infected seed or endemic but restricted to the region so far. Similarly, the finding of the Phylotype II Sequevar 1 strain from C. annuum on an experimental field in NARL-Kawanda suggests that either it was infected by soilborne strains left over from previous potato experimental fields or the pathogen was brought by contaminated tools.

Multilocus VNTR-based typing methods have been successfully used for tracking epidemiological strains of RSSC in French Guyana (N'Guessan et al. 2013), the United Kingdom (Parkinson et al. 2013), and Madagascar (Ravelomanantsoa et al.2018). The authors used amplicon size-based genotyping to type the epidemiological strains. Although time and resource consuming, sequence-based VNTR analysis, termed the TRST method (Dahyot et al. 2018), is more resolutive, with definite tandem repeat sequence counts as demonstrated in this study. As an example, Loci IP3443 of N'Guessan et al. (2013) was reported to be polymorphic and as such, included in the $R$. solanacearum MLVA-9 scheme of Ravelomanantsoa et al. (2018), whereas sequencebased TRST typing revealed that it is not polymorphic at all for isolates from Ethiopia (Abdurahman et al. 2017 and this study). Furthermore, it was also found that the polymorphism at Locus 6 of the MLVA-7 scheme of Guinard et al. (2017) was not caused by GAAGCGAAC as reported but that is was caused by TGATGCAAC at that locus at least for the strains from Uganda. Sequence-based multilocus VNTR used in this study was instrumental to track and map the epidemiological strains of RSSC in Uganda and Ethiopia, and it could be used for future epidemiological tracing and mapping of RSSC strains around the world.

Twenty-six of the $R$. solanacearum-TRST haplotypes are unique to Uganda, because none of them had identical profiles with reported strains elsewhere (N'Guessan et al. 2013; Parkinson et al. 2013; Ravelomanantsoa et al. 2018), suggesting that they are endemic to Uganda; there was no reported exchange of infected seed with those countries. However, haplotype $R$. solanacearumTRST5 had an identical profile to an epidemiological strain reported from Ethiopia (Abdurahman et al. 2017). It is likely that this strain is being disseminated via latently infected seed across the East Africa region.

The high diversity of Ugandan $R$. solanacearum Phylotype II Sequevar 1 strains and the high proportion of unique haplotypes in this study indicate that the pathogen has been endemic to the country already for a long time. These strains, reported as Pseudomonas solanacearum Biovar 2, were first isolated from

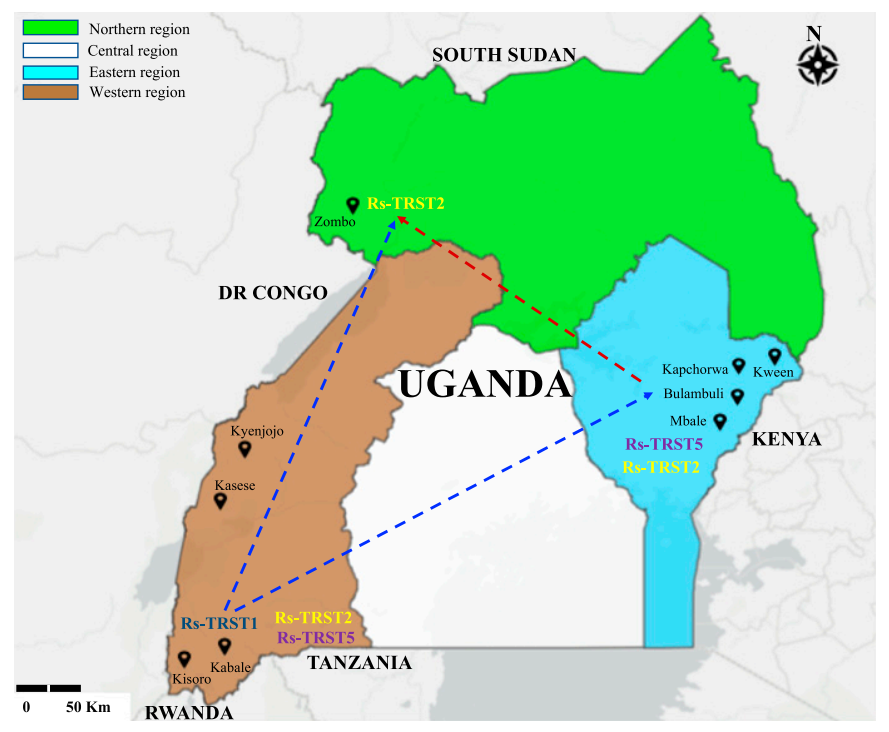

Fig. 3. Tandem repeat sequence typing (TRST) haplotype localization of epidemiologically important Phylotype II Sequevar 1 strains of Ralstonia solanacearum species complex (RSSC) in Uganda. Haplotypes $R$. solanacearum-TRST1, $R$. solanacearum-TRST2, and $R$. solanacearum-TRST5 in the western region; $R$. solanacearum-TRST2 and $R$. solanacearum-TRST5 in the eastern region; and $R$. solanacearum-TRST2 in the northern region were epidemiologically important. Blue arrows indicate the main seed potato distribution pattern from Kabale and Kisoro districts of the western region to Kween, Kapchorwa, Bulambuli, and Mbale districts of the eastern region and to Zombo district of the northern region. The red arrow indicates the secondary seed distribution pattern to Zombo district from Kween, Kapchorwa, Bulambuli, and Mbale districts of the eastern region. Inference is made that $R$. solanacearum-TRST2 and $R$. solanacearum-TRST5 are being distributed along with latently infected seed potato from Kabale and Kisoro districts to the eastern and northern regions, respectively, whereas $R$. solanacearum-TRST2 is also secondarily distributed from the eastern region to the northern region. 
potato in 1958, and they were already widespread on potatoes by 1971 (Simbwa-Bunnya 1972). In addition to the long time for diversification of VNTR loci of first introductions, multiple introductions of Sequevar 1 strains along with latently infected seed potatoes might have also contributed to the high TRST haplotype diversity. Distribution of $R$. solanacearum-TRST2 haplotype strains seems to follow a known seed potato distribution from the western region (Kabale and Kisoro districts) to the eastern region (Kween, Kapchorwa, and Mbale districts) and from the western and eastern regions to the northern region along with latently infected seed.

Phylotype I strains are known to be recombinogenic (Wicker et al. 2012; Yahiaoui et al. 2017), and hence, they are expected to diversify over time more than the monomorphic Phylotype II Sequevar 1 strains. However, despite having been reported earlier than Phylotype II strains, Phylotype I strains were less diverse than $R$. solanacearum Phylotype II strains of Uganda. It can be speculated that the low diversity is attributable to the relatively small number of isolates collected and low likelihood of multiple independent introduction of strains, because its hosts in Uganda are propagated mainly by true botanical seeds.

Common epidemiological RSSC strains are likely being disseminated and exchanged between the borders of the DRC and Uganda, the DRC and Rwanda, Burundi and Rwanda, Rwanda and Uganda, Kenya and Uganda, Kenya and Tanzania, Kenya and Ethiopia, and vice versa, because there is an active informal seed/ ware potato trade between those bordering countries. In the absence of a seed certification scheme and with the lack of regional quarantine measures in East Africa, BW of potato is becoming a very serious concern threatening the rapidly expanding potato industry as well as the food security of the growing population and millions of small holder farmers. Additional sampling of the pathogen from neighboring countries would provide a clearer population structure of RSSC strains, and it could map and trace the movement of epidemiological RSSC strains causing BW of potato in East Africa to provide evidence-based recommendations for policy makers on seed movement.

In summary, BW of potato caused by $R$. solanacearum Phylotype II is widespread in Uganda, including in seed potato fields, threatening the potato industry in the country. Although this study confirmed the presence of $R$. solanacearum (Phylotype II) and $R$. pseudosolanacearum (Phylotypes I and III) in Uganda, only Phylotype II Sequevar 1 strains were epidemiologically important for potato production in the highland districts studied, with Phylotype I Sequevar 31 being the most important for alternative vegetable hosts in the lower altitudes. Three haplotypes of the clonal $R$. solanacearum Phylotype II Sequevar 1 strains that were epidemiologically more important were likely being spread via latently infected seed. Because the geographical distribution of epidemiologically important RSSC strains has been identified and illustrated by TRST (VNTR) profiles, researchers and policy makers can develop a more effective prevention and disease management strategies.

\section{ACKNOWLEDGMENTS}

We thank John Adriko and Habibah Hannah of National Agricultural Research Laboratories, Kawanda; Abel Arenaitwe of Kachwekano Zonal Agricultural Research and Development Institute (ZARDI); and Arthur Wasukira of Buginyanya ZARDI for selecting survey districts and participating in the field surveys in their respective locations and Benson Kisinga of the International Potato Center for the mapping exercise. This research was undertaken as part of the Consultative Group for International Agricultural Research, Research Program on Roots, Tubers and Bananas.

\section{LITERATURE CITED}

Abdurahman, A., Griffin, D., Elphinstone, J. G., Struik, P. C., Schulz, S., Schulte-Geldermann, E., and Sharma, K. 2017. Molecular characterization of Ralstonia solanacearum strains from Ethiopia and tracing potential source of bacterial wilt disease outbreak in seed potatoes. Plant Pathol. 66: 826-834.

Alacho, F. O., and Akimanzi, D. R. 1993. Progress, achievements and constraints on bacterial wilt control in Uganda. Pages 32-41 in: Workshop on bacterial wilt of potato caused by Pseudomonas solanacearum, Bujumbura, Burundi.

Alvarez, B., Lopez, M., and Biosca, G. 2008. Survival strategies and pathogenicity of Ralstonia solanacearum phylotype II subjected to prolonged starvation in environmental water microcosms. Microbiology 154:3590-3598.

Buddenhagen, I. 1986. Bacterial wilt revisited. Pages 126-143 in: Bacterial Wilt Disease in Asia and the South Pacific, G. J. Persley, ed. ACIAR, Canberra, ACT, Australia.

Buddenhagen, I. W., Sequeira, L., and Kelman, A. 1962. Designation of races in Pseudomonas solanacearum. (Abstr.) Phytopathology 52:726.

Chesneau, T., Maignien, G., Boyer, C., Chéron, J. J., Roux-Cuvelier, M., Vanhuffel, L., Poussier, S., and Prior, P. 2018. Sequevar diversity and virulence of Ralstonia solanacearum Phylotype I on Mayotte Island (Indian Ocean). Front. Plant Sci. 8:2209.

Dahyot, S., Lebeurre, J., Argemi, X., François, P., Lemée, L., Prévost, G., and Pestel-Caron, M. 2018. Multiple-locus variable number tandem repeat analysis (MLVA) and tandem repeat sequence typing (TRST), helpful tools for subtyping Staphylococcus lugdunensis. Sci. Rep. 8:11669.

Elphinstone, J. G. 2005. The current bacterial wilt situation: A global overview. Pages 9-28 in: Bacterial Wilt Disease and the Ralstonia solanacearum Species Complex. C. Allen, P. Prior, and A. C. Hayward, eds. American Phytopathological Society, St. Paul, MN.

FAOSTAT. 2017. http://www.fao.org/faostat/en/\#data/QC

Fegan, M., and Prior, P. 2005. How complex is the Ralstonia species complex. Pages 449-461 in: Bacterial Wilt Disease and the Ralstonia solanacearum Species Complex. C. Allen, P. Prior, and A. C. Hayward, eds. American Phytopathological Society, St. Paul, MN.

Fouché-Weich, J., Poussier, S., Trigalet-Demery, D., Berger, D., and Coutinho, T. 2006. Molecular identification of some African strains of Ralstonia solanacearum from eucalypt and potato. J. Gen. Plant Pathol. 72:369-373.

Fuglie, K. 2007. Priorities for potato research in developing countries: Results of a survey. Am. J. Potato Res. 84:353-365.

Gildemacher, P., Demo, P., Barker, I., Kaguongo, W., Woldegiorgis, G., Wagoire, W., Wakahiu, M., Leeuwis, C., and Struik, P. 2009. A description of seed potato systems in Kenya, Uganda and Ethiopia. Am. J. Potato Res. 86:373-382.

Guinard, J., Anne, L., Fabien, G., Stéphane, P., and Emmanuel, W. 2017. New multilocus variable-number tandem-repeat analysis (MLVA) scheme for fine-scale monitoring and microevolution-related study of Ralstonia pseudosolanacearum Phylotype I populations. Appl. Environ. Microbiol. 83: e03095-16.

Haubold, B., and Hudson, R. 2000. LIAN 3.0: Detecting linkage disequilibrium in multilocus data. Bioinformatics 16:847-849.

Hayward, A. 1994. The hosts of Pseudomonas solanacearum. Pages 9-24 in: Bacterial Wilt: The Disease and Its Causative Agent, Pseudomonas solanacearum, Hayward, A. C., and Hartman, G. L., eds. CAB International, Wallingford, United Kingdom.

Hayward, A. C. 1964. Characteristics of Pseudomonas solanacearum. J. Appl. Bacteriol. 27:265-277.

Hayward, A. C. 1974. Latent infections by bacteria. Annu. Rev. Phytopathol. 12:87-97.

Hayward, A. C. 1990. Diagnosis, distribution and status of groundnut bacterial wilt. Pages 12-17 in: Bacterial Wilt of Groundnut. Proceedings of an ACIAR/ICRISAT Collaborative Research Planning Meeting. K. J. Middleton and A. C. Hayward, eds. Burnett Printing, Kingaroy, Queensland, Australia.

Hunter, P., and Gaston, M. 1988. Numerical index of the discriminatory ability of typing systems: An application of Simpson's index of diversity. J. Clin. Microbiol. 26:2465-2466.

Janse, D. 1996. Potato brown rot in Western Europe-history, present occurrence and some remarks on possible origin, epidemiology and control strategies. Bull. OEPP/EPPO 26:679-695.

Janse, J. D., Beld, H. E. d., Elphinstone, J., Simpkins, S., Tjou-Tam-Sin, N. A. A., and Vaerenbergh, J. v. 2004. Introduction to Europe of Ralstonia solanacearum biovar 2, race 3 in Pelargonium zonale cuttings. J. Plant Pathol. 86:147-155.

Kaguongo, W., Gildemacher, P., Demo, P., Wagoire, W., Kinyae, P., Andrade, J., Forbes, G., and Fuglie, K. 2008. Farmer practices and adoption of improved potato varieties in Kenya and Uganda. Social Sciences Working Paper 2008-5. CIP, Lima, Peru.

Kakuhenzire, R., Lemaga, B., Kashaija, I. N., Ortiz, O., and Mateeka, B. 2013. Effect of Crotalaria falcata in crop rotation and fallowing on potato 
bacterial wilt incidence, disease severity and latent infection in tubers and field soil. Biopestic. Int. (Jalandhar) 6:182-194.

Kansiime, M., Mulema, J., Karanja, D., Romney, D., and Day, R. 2016. Crop pests and disease management in Uganda: Status and investment needs. Final report. CAB International, Wallingford, U.K.

Katafiire, M., Adipala, E., Lemaga, B., Olanya, M., El-Bedewyand, R., and Ewell, P. 2005. Management of bacterial wilt of potato using one-season rotation crops in southwestern Uganda. Pages 197-203 in: Bacterial Wilt Disease and the Ralstonia solanacearum Species Complex. C. Allen, P. Prior, and A. C. Hayward, eds. American Phytopathological Society, St. Paul, MN.

Lemaga, B., Kakuhenzire, R., Kassa, B., Ewell, P., and Priou, S. 2005. Integrated control of potato bacterial wilt in eastern Africa: The experience of African highland initiative. Pages 145-157 in: Bacterial Wilt Disease and the Ralstonia solanacearum Species Complex. C. Allen, P. Prior, and A. C. Hayward, eds. American Phytopathological Society, St. Paul, MN.

Lemaga, B., Kanzikwera, R., Kakuhenzire, R., Hakiza, J., and Manzi, G. 2001. The effect of crop rotation on bacterial wilt incidence and potato tuber yield. Afr. Crop Sci. J. 9:257-266.

Low, J. W. 1997. Threats to the sustainability of potato production in SouthWest Uganda. Afr. Crop Sci. J. 5:395-412.

Mahbou Somo Toukam, G., Cellier, G., Wicker, E., Guilbaud, C., Kahane, R., Allen, C., and Prior, P. 2009. Broad diversity of Ralstonia solanacearum strains in Cameroon. Plant Dis. 93:1123-1130.

Mansfield, J., Genin, S., Magori, S., Citovsky, V., Sriariyanum, M., Ronald, P., Dow, X., Verdier, V., Beer, S., Machado, M., Toth, I., and Salmond, G. 2012. Top 10 plant pathogenic bacteria in molecular plant pathology. Mol. Plant Pathol. 13:614-629.

McClean, A. P. D. 1930. The bacterial wilt disease of peanut (Arachis hypogaea L.). S. Afr. Dep. Agric. Sci. Bull. (Beijing) 87:14.

Mokrousov, I. 2017. Revisiting the Hunter Gaston discriminatory index: Note of caution and courses of change. Tuberculosis (Edinb.) 104:20-23.

Namugga, P., Melis, R., Sibiya, J., and Barekye, A. 2017. Participatory assessment of potato farming systems, production constraints and cultivar preferences in Uganda. Aust. J. Crop Sci. 11:932-940.

Nei, M. 1978. Estimation of average heterozygosity and genetic distance from a small sample of individuals. Genetics 89:583-590.

N'Guessan, C., Brisse, S., Le Roux-Nio, A., Poussier, S., Koné, D., and Wicker, E. 2013. Development of variable number of tandem repeats typing schemes for Ralstonia solanacearum, the agent of bacterial wilt, banana Moko disease and potato brown rot. J. Microbiol. Methods 92:366-374.

Opina, N., Tavner, F., Hollway, G., Wang, F., Li, H., Maghirang, R., Fegan, M., Hayward, C., Krishnapillai, V., Hong, F., Holloway, W., and Timmis, N. 1997. A novel method for development of species and strain-specific DNA probes and PCR primers for identifying Burkholderia solanacearum (formerly Pseudomonas solanacearum). Asia Pac. J. Mol. Biol. Biotechnol. 5: 19-30.

Opio, A. F. 1988. Pseudomonas solanacearum E.F. Smith in Uganda: A preliminary study. 15th International Congress of Plant Pathology. Kyoto, Japan.

Parkinson, N., Bryant, R., Bew, J., Conyers, C., Stones, R., Alcock, M., and Elphinstone, J. 2013. Application of variable-number tandem-repeat typing to discriminate Ralstonia solanacearum strains associated with English watercourses and disease outbreaks. Appl. Environ. Microbiol. 79:6016-6022.

Poussier, S., Trigalet-Demery, D., Vandewalle, P., Goffinet, B., Luisetti, J., and Trigalet, A. 2000. Genetic diversity of Ralstonia solanacearum as assessed by PCR-RFLP of the hrp gene region, AFLP and 16S rRNA sequence analysis, and identification of an African subdivision. Microbiology 146: 1679-1692.
Ravelomanantsoa, S., Verniere, C., Rieux, A., Costet, L., Chiroleu, F., Arribat, S., Cellier, G., Pruvost, O., Poussier, S., Robene, I., Guerin, F., and Prior, P. 2018. Molecular epidemiology of bacterial wilt in the Madagascar highlands caused by Andean (Phylotype IIB-1) and African (Phylotype III) brown rot strains of the Ralstonia solanacearum species complex. Front. Plant Sci. 8:2258.

Rodrigues, L. M. R., Destefano, S. A. L., Silva, M. J. d., Costa, G. G. L., and Maringoni, A. C. 2012. Characterization of Ralstonia solanacearum strains from Brazil using molecular methods and pathogenicity tests. J. Plant Pathol. 94:505-516.

Safni, I., Cleenwerck, I., De Vos, P., Fegan, M., Sly, L., and Kappler, U. 2014. Polyphasic taxonomic revision of the Ralstonia solanacearum species complex: Proposal to emend the descriptions of Ralstonia solanacearum and Ralstonia syzygii and reclassify current $R$. syzygii strains as Ralstonia syzygii subsp. syzygii subsp. nov., $R$. solanacearum phylotype IV strains as Ralstonia syzygii subsp. indonesiensis subsp. nov., banana blood disease bacterium strains as Ralstonia syzygii subsp. celebesensis subsp. nov. and $R$. solanacearum phylotype I and III strains as Ralstonia pseudosolanacearum sp. nov. Int. J. Syst. Evol. Microbiol. 64:3087-3103.

Selander, R., Caugant, D., Ochman, H., Musser, J., Gilmour, M., and Whittam, T. 1986. Methods of multilocus enzyme electrophoresis for bacterial population genetics and systematics. Appl. Environ. Microbiol. 51:873-884.

Simbwa-Bunnya, M. 1972. Resistance of groundnut varieties to bacterial wilt (Pseudomonas solanacearum) in Uganda. East Afr. Agric. For. J. 37: 341-343.

Sola, C., Filliol, I., Legrand, E., Lesjean, S., Locht, C., Supply, P., and Rastogi, N. 2003. Genotyping of the Mycobacterium tuberculosis complex using MIRUs: Association with VNTR and spoligotyping for molecular epidemiology and evolutionary genetics. Infect. Genet. Evol. 3:125-133.

Struik, P. C., and Wiersema, S. G. 1999. Seed Potato Technology. Wageningen Pers, Wageningen, The Netherlands.

Stulberg, M. J., and Huang, Q. 2016. A computer program for fast and easy typing of a partial endoglucanase gene sequence into genospecies and sequevars 1 \& 2 of the Ralstonia solanacearum species complex. J. Microbiol. Methods 123:101-107.

Swanson, J., Montes, L., Mejia, L., and Allen, C. 2007. Detection of latent infections of Ralstonia solanacearum Race 3 biovar 2 in geranium. Plant Dis. 91:828-834.

Tamura, K., Stecher, G., Peterson, D., Filipski, A., and Kumar, S. 2013. MEGA6: Molecular Evolutionary Genetics Analysis Version 6.0. Mol. Biol. Evol. 30:2725-2729.

Tusiime, G., Adiphala, E., Opio, F., and Bhagsari, A. S. 1996. Occurance of Pseudomonas solanacearum latent infection in potato tubers and weeds in highland Uganda. Afr. J. Plant Prot. 6:108-118.

Uganda Bureau of Statistics; Macro International Inc. 2015. Uganda Demographic and Health Survey 2010-2011. UBOS and Macro International, Calverton, MD

van Overbeek, L., Bergervoet, J., Jacobs, F., and van Elsas, J. 2004. The lowtemperature-induced viable-but-nonculturable state affects the virulence of Ralstonia solanacearum biovar 2. Phytopathology 94:463-469.

Wicker, E., Lefeuvre, P., De Cambiaire, J., Lemaire, C., Poussier, S., and Prior, P. 2012. Contrasting recombination patterns and demographic histories of the plant pathogen Ralstonia solanacearum inferred from MLSA. ISME J. 6:961-974.

Yahiaoui, N., Chéron, J.-J., Ravelomanantsoa, S., Hamza, A. A., Petrousse, B., Jeetah, R., Jaufeerally-Fakim, Y., Félicité, J., Fillâtre, J., Hostachy, B., Guérin, F., Cellier, G., Prior, P., and Poussier, S. 2017. Genetic diversity of the Ralstonia solanacearum species complex in the southwest Indian Ocean islands. Front. Plant Sci. 8:2139. 